\title{
HUBUNGAN HARGA DAN KUALITAS PRODUK DENGAN KEPUASAN PELANGGAN PADA TOKO PERLENGKAPAN BAJU SEKOLAH ELIS KOTA BENGKULU
}

\author{
Siti Hanila, Rahmad Hidayat \\ Program Studi Manajemen Fakultas Ekonomi Universitas Dehasen Bengkulu \\ st.hanila@gmail.com
}

\begin{abstract}
ABSTRAK
Siti Hanila, Rahmad Hidayat; Tujuan penelitian ini adalah untuk mengetahui hubungan harga dan kualitas produk dengan kepuasan pelanggan pada toko perlengkapan baju sekolah Elis Kota Bengkulu. Sampel dalam penelitian ini sebanyak 50 orang konsumen yang melakukan pembelian perlengkapan baju sekolah pada toko perlengkapan baju sekolah Elis Kota Bengkulu, karena semua populasi dalam penelitian ini dijadikan sampel, maka pengambilan sampel dilakukan dengan menggunakan teknik sampling accidental. Metode pengumpulan data menggunakan kuesioner dan metode analisis yang digunakan adalah analisis korelasi rank spearman dan pengujian kebenaran data dengan uji $t$.

Berdasarkan hasil penelitian harga memiliki hubungan yang sedang dengan kepuasan pelanggan pada toko perlengkapan baju sekolah Elis Kota Bengkulu dengan nilai korelasi sebesar 0,537, Dengan demikian harga yang ditawarkan oleh pihak toko perlengkapan baju sekolah Elis Kota Bengkulu relatif sedang atau tidak terlalu mahal maupun tidak terlalu murah. Hasil ini diperkuat dengan hasil uji hipotesis bahwa $t_{\text {fttumg }}$ lebih besar dari $t_{\text {tabel }}(4,408>1,677)$. Artinya harga mempunyai hubungan yang signifikan dengan kepuasan pelanggan pada toko perlengkapan baju sekolah Elis Kota Bengkulu. Korelasi rank spearman untuk hubungan kualitas produk dengan kepuasan pelanggan pada toko perlengkapan baju sekolah Elis Kota Bengkulu memiliki korelasi yang kuat dengan nilai korelasi sebesar 0,604, ini berarti Ini berarti bahwa semakin baik kualitas yang di perjual belikan oleh toko perlengkapan baju sekolah Elis kota Bengkulu maka akan semakin tinggi juga tingkat kepuasan pelanggan pada perlengkapan baju sekolah pada toko Elis kota Bengkulu. Hal ini diperkuat dengan hasil uji hipotesis bahwa $t_{\text {ftwng }}$ lebih besar dari $t_{\text {take }}(5,246>1,677)$. Artinya kualitas produk mempunyai hubungan yang signifikan dengan kepuasan pelanggan pada toko perlengkapan baju sekolah Elis Kota Bengkulu.
\end{abstract}

\section{ABSTRACT}

Siti Hanila, Rahmad Hidayat; The aim of this study is to know the relationship of price and product quality with customer satisfaction at Elis school uniform shop of Bengkulu city. The sample in this study were 50 consumers who purchased school uniform at Elis school uniform shop of Bengkulu city, because all the population in this study were sampled, so the sampling was done by using accidental sampling technique. Data collection methods used is questionnaires and analytical methods used are rank spearman correlation analysis and testing the data with $t$ test.Based on the results of study the price has a relationship with the customer satisfaction at Elis school uniform shop of Bengkulu citywith a correlation value of 0.537, thus the price offered by the shop is relatively or not too expensive or not too cheap. This result is reinforced by hypothesis test result that $t_{\text {count }}$ is greater than $t$ table $(4.408>1.677)$. This means that the price has a significant relationship with customer satisfaction at Elis school uniform shop of Bengkulu city.Rank spearman correlation for the relationship of product quality with customer satisfaction at Elis school uniform shop of Bengkulu cityhas a strong correlation with correlation value of 0.604, it means that the better quality of the trade by Elis school uniform shop, the higher level of customerssatisfaction. This is reinforced by the hypothesis test result that $t$ count is greater than $t$ table (5.246>1.677). This means that the product quality has a significant relationship with customer satisfaction at Elis school uniform shop of Bengkulu city.

Key Words: Price, Product Quality, Customer Satisfaction

\section{LATAR BELAKANG}

Dunia bisnis yang tumbuh dengan pesat menjadi tantangan maupun ancaman bagi para pelaku usaha agar dapat memenangkan persaingan dan mempertahannkan kelangsungan hidup perusahaannya. Menurut Oliver (2007:3) menjelaskan bahwa kepuasan pelanggan perupakan bagian dari pemasaran dan memainkan peran penting di pasar. Strategi pemasaran yang berorintasi pada konsumen membuat perusahaan harus memahami perilaku maupun kebutuhan konsumen untuk mencapai kepuasan 
konsumen. Seiring dengan hal tersebut konsep pemasaran pun turut berkembang, kegiatan pemasaran sekarang udah mulai difokuskan pada pemuasan kebutuhan konsumen dan meningkatkan kepusan pelanggan yang pada akhirnya akan tercipta rasa nyaman kepada kualitas produk yang ditawarkan seperti dengan menawarkan berbagai kelebihan dan keunikan dari masing-produk tersebut.

Hal ini membuat para konsumen mempunyai banyak alternatif dalam pemilihan produk yang ditawarkan oleh produsen. Tetapi dengan semakin banyak produk yang ditawarkan maka semakin ketat pula persaingan yang terjadi dalam dunia usaha. Persaingan yang semaki ketat ini menuntut para pelaku bisnis untuk mampu memaksimalkan kinerja perusahaannya agar dapat bersaing dipasar.

Kualitas produk adalah faktor penentu kepuasan konsumen setelah melakukan pembelian dan pemakaian terhadap suatu produk. Dengan kualitas produk yang baik maka keinginan dan kebutuhan konsumen terhadap suatu produk akan terpenuhi. Menurut Kotler dan Amsrong (2008:152) kualitas produk menggambarkan sejauh mana kemampuan produk tersebut dalam dalam memenuhi kebutuhan konsumen. Definisi dari kualitas produk mencerminkan kemampuan produk untuk menjalannkan tugasnya yang mencakup daya tahan kehandalan atau kemajuan, kekuatan, kemudahan dalam pengemasan dan reparasi produk dan ciri-ciri lainnya. Semakin sesuai standar yang ditetapkan maka akan dinilai produk tersebut semakin berkualitas.

Selain ditinjau dari kualitas suatu produk, faktor harga juga merupakanhal penting yang menjadi pertimbangan konsumen untuk dalam mengambil keputusan pembelian produk. Definisi harga menurut Kotler dan Amstrong (2008:439) adalah sejumlah uang yang dibebankan atas suatu produk atau jasa atau jumlah dari seluruh nilai yang ditukar oleh konsumen atau manfaat karena memiliki atau menggunakan produk atau menggunakan produk atau jasa tersebut. Harga merupakan salah satu faktor penting dalam penjualan, banyak perusahaan bangkrut karena mematok harga yang tidak cocok dipenjualan. Harga yang ditetapkan harus sesuai dengan perekonomian konsumen, agar konsumen dapat membeli barang tersebut . Sedangkan bagi konsumen, agar konsumen dapat membeli barang tersebut. Sedangkan bagi konsumen, harga merupakan bahan pertimbangan dalam pengambilan keputusan.

Keputusan pelanggan merupakan suatu tingkatan dimana kebutuhan, keinginan da $\mathrm{n}$ harapan dari pelanggan dapat terpenuhi yang akan mengakibatkan terjadinya pembelian ulang atau berlangganan. Sebuah perusahaan harus mempunyai strategi-strategi dalam memasarkan produknya, agar konsumen dapat dipertahannkan keberadaannya atau lebih ditingkatkan lagi jumlahnya. Jika konsumen merasa puas, maka ia akan mel perlakukan pembelian secara berulang-ulang. Pembelian yangbeulang-ulang pada satu produk pada perusahaan yang sama dapat dikatakan bahwa konsumen tersebut mempunyai loyalitas terhadap perusahaan tersebut. Untuk memberikan kepuasan terhadap konsumen, perusahaan harus dapat menjual barang atau jasa dengan kualitas yang paling baik dengan harga yang layak sesuai dengan apa yang didapatkan. Perusahaan juga melakukan strategi-strategi untuk membentuk kepuasan konsumen dengan memberikan pelayanan dan produk yang berkualitas dengan demikian para konsumen akan terasa terpuaskan terhadap perusahaan yang telah memberikan mereka sesuatu yang terbaik.

Toko perlengkapan baju sekolah Elis mempunyai 2 toko ditempat pasar minggu dipasar bertingkat kota Bengkulu. Toko perlengkapan baju sekolah Elis ini memproduksi sendiri produknya seperti baju, celana dll, karena memproduksi sendiri produk yang mereka perjual belikan yaitu harga dan kualitas berbeda dengan pesaing yang lain karena mereka yang menentukan harga produk yang diproduksi. Toko Elis juga menyediakan berbagai alat perlengkapan sekolah dengan beberapa bahan dengan kualitas yang berbeda-beda dan harga yang sesuai dengan kualitas produk yang diinginkan. Berdasarkan uraian diatas maka peneliti tertarik untuk mengangkat judul "Hubungan Harga dan Kualitas Produk dengan Kepuasan Pelanggan pada Toko Perlengkapan Baju Sekolah Elis Kota Bengkulu"

\section{Landasan Teori}

\section{Bauran Pemasaran (Marketing Mix)}

Suatu bisnis mungkin harus mengubah tujuan dan startegi persaingan ketika posisi persaingan industri dan bisnisnya matang dan stabil. Strategi pemasaran harus dirumuskan sedemikian rupa sehingga memberikan nilai kepada konsumen dan menjaga keunggulan kompetitif yang abadi. Konsep pemasaran , sebagai seni menjual produk dalam mencapai tujuan pemasaran menegaskan bahwa kunci untuk mencapai tujuan yang ditetapkan adalah perusahaan tersebut harus menjadi lebih eekif dibandingkan para pesaing dalam menciptakan, menyerahkan dan mengkomunikasikan nilai pelanggan pada pasar sasaran yang terpilih (Kotler, 2007:6)

Oleh sebab itu bauran pemasaran digunakan sebagai variabel-variabel pemasaran untuk mengimlementasikan dan merakit program demi menciptakan, mengkomunikasikan dan menyerahkan nilai bagi konsumen. Bauran pemasaran (Marketing Mix) adalah variabel-variabel pemasaran yang dapat dikontrol, yang akan dikombinasikan oleh perusahaan untuk memperoleh hasil yang maksimal (Kotler, 
2007:27). Alat-alat ini dikenal dengan 4 P yaitu Produk (Product), Harga (Price), Tempat( Place) dan Promosi (Promotion)

Menurut Daniel dan Gates (2007:4) mengemukakan bahwa : pemasaran adalah proses merencanakan dan melaksanakan konsep, memberi harga, melakukan promosi, dan mendistribusikan ide, barang danjasa untuk menciptakan pertukaran yang memenuhi tujuan individu dan organisasi .

\section{Harga}

Harga merupakan salah satu bagian dari bauran pemasaran (Marketing Mic) yang sangat penting dalam pemasaran produk.Keberhasilan perusahaan salah satunya ditentukan oleh keberhasilan dari perusahaan itu dalam menetapka harga.

a. Pengertian harga

Menurut Simamora (2007:30) harga adalah sejumlah nilai dipertukarkan untuk memperoleh suatu produk. Sedangkan menurut Suwarman(2011:303) harga adalah atribut produk atau jasa yang paling sering digunakan oleh sebagian besar konsumen untuk mengevaluasi produk.

b. Langkah-langkah penetapan pasar

Menurut Simamora (2007:195) penetapan harga meliputi langkah -langkah sebagai berikut :

1. Analisis keadaan pasar
a. Bentuk pasar
b. Pasar persaingan sempurna
c. Persaingan monopolistik
d. Pasar Oligopolistik
e. Monopoli pasar

2. Elastisitas permintaan terhadap harga

3. Faktor-faktor yang nenpengaruhi sensitifitas harga.

4. Analiisis interval dan preferensi harga konsumen

5. Analisis persaingan

a. Mengidentifikasi pembatas-pembatas harga

b. Menetapkan sasaran

c. Analisis potensi keuntungan

d. Menetapkan harga awal

\section{Kualitas Produk}

Menurut Tjiptono (2007:77) kualitas produk adalah kualitas meliputi usaha memenuhi atau melebihi harapan pelanggan, kualitas mencakup produk, jasa, manusia, proses, dan lingkungan. Kualitas merupakan kondisi yang selalu berubah (misalnya apa yang dianggap merupakan kualitas saat ini mungkin dianggap kuarang berkualitas pada masa mendatang.

Menurut Kotler (2008:329) mengungkapkan ada delapan indikator kualitas produk yaitu:1.Bentuk (performance), 2.Keistimewaan (features) , 3.Keandalan(realiability), 4 Mutu kinerja (conformance), 5.Daya tahan(durability), 6 Pelayanan(service ability), Keindahan/gaya (aesthetics).

\section{Kepuasan Konsumen}

Menurut Amir (2008:35) kepuasan konsumen adalah sejauh mana manfaat sebuah produk dirasakan (perceived) sesuai dengan apa yang diharapka pelanggan. Sedangkan menurut Kotler (2009:74) mengatakan bahwa kepuasan konsumen merupakan tingkat perasaan seseorang setelah membandingkan antara kinerja produk yang ia rasakan dengan harapannya.

Kepuasan pelanggan adalah rangkuman kondisi psikologis yang hasilkan ketika emosi yang mengelilingi harapan tidak cocok dan dilipat gandakan oleh perasaan -perasaan yang terbentuk mengenai pengalaman pengkonsumsian.

\section{Kompensasi kepuasan konsumen}

Seperti yang telah dikemukakan diatas bahwa ada banyak pengertian kepuasan konsumen. Menurut Giese \& Cote ( 2000:293) sekalipun banyak definisi kepuasan konsumen, namun secara umum tetap mengarah kepada tiga komponen yaitu :

1. Respon: Tipe dan intensitas

2. Fokus

3. Waktu respon 


\section{Ciri-ciri konsumen puas}

Kotler,(2009:89) menyatakan ciri-ciri konsumen yang merasa puas sebagai berikut:

1. Loyal terhadap produk

2. Adanya komunikasi dari mulut ke mulut yang bersifat positif

3. Perusahaan menjadi pertimbangan utama ketika membeli merek lain

\section{Tipe-tipe kepuasan dan ketidakpuasan}

Menurut Tjiptono (2007:101) atribut pembentukan kepuasan terdiri dari :

1. Kesesuaian harapan

a. Produk yang diperoleh sesuai atau melebihi dengan yang diharapkan

b. Pelayanan oleh karyawan yang dipeoleh sesuai atau melebihi dengan yang diharapkan.

c. Fasilitas penunjang yang didapat sesuai atau melebihi dengan yang diharapkan.

2. Minat berkunjung kembali

Merupakan kesediaan konsumen untuk berkunjung kembali atau melakukan pembelian ulang terhadap produk terkait, meliputi :

a. Berminat untuk berkunjung kembali karena pelayanan yang diberikan oleh karyawan memuaskan

b. Berminat untuk berkunjung kembali karena nilai dan manfaat yang dipeoleh setelah mengkonsumsi produk.

c. Berminat untuk berkunjung kembali karena fasilitas penunjang yang disediakan memadai.

3. Kesediaan merekomendasi Merupakan kesediaan konsumen untuk mrekomendasikan produk yang telah dirasakanya kepada teman atau keluarga, meliputi :

a. Menyarankan teman atau kerabat untuk membeli produk yang ditawarkan karena pelayanan yang memuaskan.

b. Menyarankan teman atau kerabat untuk membeli produk yang ditawarkan karena fasilitas penunjang yang disediakan memadai

c. Menyarankan teman atau karabat untuk membeli produk ang ditawarkan karena nilai atau manfaat yang didapat.

\section{HIPOTESIS}

Hipotesis dalam penelitian ini adalah sebagai berikut :

1. Diduga adanya hubungan yang positif dan signifikan antara harga dengan kepuasan pelanggan pada toko perlengkapan baju Sekolah Elis Kota Bengkulu

2. Diduga adanya hubungan yang positif dan signifikan antara kualitas produk dengan kepuasan pelanggan pada toko perlengkapan baju Sekolah Elis Kota Bengkulu

HASIL DAN PEMBAHASAN

Hubungan Harga Dengan kepuasan Pelanggan Pada Toko Perlengkapan Baju Sekolah Elis Kota Bengkulu

Berdasarkan perhitungan korelasi rank spearman untuk hubungan harga dengan kepuasan pelanggan pada toko perlengkapan baju sekolah Elis Kota Bengkulu diketahui data-data sebagai berikut:

$$
\begin{aligned}
\mathrm{n} & =50 \\
\Sigma^{b} t t^{2} & =9.660,75
\end{aligned}
$$

Selanjutnya dari data tersebut akan dimasukan kedalam rumus rank spearman sebagai berikut:

$$
\begin{aligned}
& \rho=1-\frac{6(9.660,75)}{\left.50,50^{2}-1\right)} \\
& \rho=1-\frac{57.964,5}{50(2.500-1)} \\
& \rho=1-\frac{57.964,5}{50(2.494)} \\
& \rho=1-\frac{57.964,5}{124,950}
\end{aligned}
$$




$$
\begin{aligned}
& \rho=1-0,463 \\
& \rho=0,537
\end{aligned}
$$

Diketahui bahwa dari perhitungan nilai rank spearman besar korelasi harga dengan kepuasan pelanggan pada toko perlengkapan baju sekolah Elis Kota Bengkulu sebesar 0,537. Artinya besarnya nilai hubungan antara harga dengan kepuasan pelanggan pada toko perlengkapan baju sekolah Elis Kota Bengkulu 0,537, yang berarti memiliki korelasi yang sedang karena angka 0,537 terletak diantara 0,40 0,599. Dengan demikian harga yang ditawarkan oleh pihak toko perlengkapan baju sekolah Elis Kota Bengkulu relatif sedang atau tidak terlalu mahal maupun tidak terlalu murah.

\section{Hubungan Kualitas Produk Dengan Kepuasan Pelanggan Pada Toko Perlengkapan Baju Sekolah Elis Kota Bengkulu}

Berdasarkan lampiran 10 tabel penolong perhitungan korelasi rank spearman untuk hubungan kualitas produk dengan kepuasan pelanggan pada toko perlengkapan baju sekolah Elis kota Bengkulu:

$$
\begin{array}{ll}
\mathrm{n} & : 50 \\
\sum b i^{2} & : 8249,5
\end{array}
$$

Selanjutnya dari data tersebut akan dimasukkan kedalam rumus rank spearman sebagai berikut:

$$
\begin{aligned}
& \rho=1-\frac{6(8249,5)}{\left.50,50^{2}-1\right)} \\
& \rho=1-\frac{49,4.97}{50(2,500-1)} \\
& \rho=1-\frac{49.497}{50(2,499)} \\
& \rho=1-\frac{49,497}{124,950} \\
& \rho=1-0,396 \\
& \rho=0,604
\end{aligned}
$$

Diketahui bahwa dari perhitungan nilai rank spearman besar korelasi kualitas produk dengan kepuasan pelanggan pada toko perlengkapan baju sekolah Elis kota Bengkulu sebesar 0, 604.

Artinya besarnya korelasi hubungan antara kualitas produk dengan kepuasan pelanggan pada toko perlengkapan baju sekolah Elis kota Bengkulu adalah sebesar 0,604 yang berarti memiliki korelasi yang kuat karena angka 0,604 terletak diantara angka 0,60-0,799. Ini berarti bahwa semakin baik kualitas yang di perjual belikan oleh toko perlengkapan baju sekolah Elis kota Bengkulu maka akan semakin tinggi juga tingkat kepuasan pelanggan pada perlengkapan baju sekolahpada toko Elis kota Bengkulu. Hal ini menggambarkan dengan adanya kualitas produk yang baik akan meningkatkan kepuasan pelanggan untuk melakukan pebelian kembali kepada toko tersebut.

\section{Uji Hipotesis}

Selanjutnya untuk mengetahui apakah antara variabel X dan variabel Y memiliki hubungan yang signifikan maka dilakukan uji hipotesis yaitu uji t.

\section{Uji Hipotesis Hubungan Harga Dengan Kepuasan Pelanggan Pada Toko Perlengkapan Baju Sekolah Elis Kota Bengkulu.}

Dari hasil perhitungan korelasi rank spearman untuk hubungan harga dengan kepuasan pelanggan pada toko perlengkapan baju sekolah Elis Kota Bengkulu diperoleh nilai $\rho=0,537$ dengan $n=50$, maka dapat diketahui nilai t-hitung sebagai berikut:

$$
\begin{aligned}
& t_{\text {hitung }}=\sqrt[n]{\frac{n-2}{1-r^{2}}} \\
& t_{\text {htwung }}=0,537 \sqrt{\frac{50-2}{1-0,537^{2}}}
\end{aligned}
$$




$$
\begin{aligned}
& t_{\text {fitung }}=0,537 \sqrt{\frac{48}{1-0,288}} \\
& t_{\text {manug }}=0,537 \sqrt{\frac{48}{0,712}} \\
& t_{\text {hitumg }}=0,537 \sqrt{67,4: 15} \\
& t_{\text {httumg }}=0,537(8,210) \\
& t_{\text {hitung }}=4,408 \\
& \text { nilai } t_{\text {hitumg }} \text { sebesar 4,408 kemudian dibandingkan dengan nilai tobsi } \\
& \text { of signifikanditetapkan 95\% dengan perhitungan satu arah dan } \mathrm{dk}=\mathrm{n}-2=50-2=48 \text {, yaitu } \\
& \text { diketahui nilai } t_{\text {tabei }} \text { sebesar 1,677 dengan demikian diketahui bahwa } t_{\text {fittumg }} \text { lebih besar } \\
& \text { dari } t_{\text {taket }}(4,408>1,677) \text {. }
\end{aligned}
$$

\section{Uji Hipotesis Hubungan Kualitas Produk Dengan Kepuasan Pelanggan Pada Toko Perlengkapan Baju Sekolah Elis Kota Bengkulu.}

Dari hasil perhitungan korelasi rank spearman untuk hubungan kualitas produk dengan kepuasan pelanggan pada toko perlengkapan baju sekolah Elis Kota Bengkulu diperoleh nilai $\rho=0,604$ dengan $\mathrm{n}=50$, maka dapat diketahui nilai t-hitung sebagai berikut:

$$
\begin{aligned}
& t_{\text {mawng }}=r \sqrt{\frac{x-2}{1-r^{2}}} \\
& t_{\text {hitwag }}=0,604 \sqrt{\frac{50-2}{1-0,604^{2}}} \\
& t_{\text {httung }}=0,504 \sqrt{\frac{48}{1-0,364}} \\
& t_{\text {htwwing }}=0,604 \sqrt{\frac{48}{0,636}} \\
& t_{\text {tot }}=0,604 \sqrt{75,471} \\
& t_{\text {hituing }}=0,604(8,687) \\
& \boldsymbol{t}_{\text {hitung }}=5,246
\end{aligned}
$$

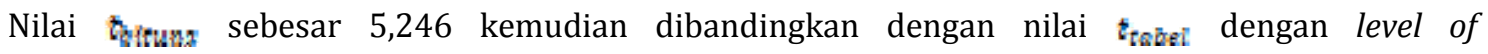
signifikanditetapkan 95\% dengan perhitungan satu sisi dan $\mathrm{dk}=\mathrm{n}-2=50-2=48$, yaitu diketahui nilai

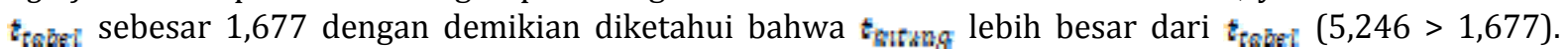
Artinnya adalah $F_{0 e}$ ditolak dan $F_{\mathrm{wz}}$ diterima atau kualitas produk mempunyai hubungan yang signifikan dengan kepuasan pelanggan pada toko perlengkapan baju sekolah Elis Kota Bengkulu

\section{Pembahasan}

Berdasarkan hasil penilitian mengenai hubungan harga dan kualitas produk dengan kepuasan pelanggan pada toko perlengkapan baju sekolah Elis Kota Bengkulu dengan cara menyebarkan kuesioner kepada 50 orang responden, maka dapat diketahui bahwa harga dan kualitas produk memiliki hubungan yang signifikan dengan kepuasan pelanggan pada toko perlengkapan baju sekolah Elis Kota Bengkulu. Berdasarkan pengujian analisis korelasi rank spearman dan uji hipotetis t maka dapat dijelaskan hasil dari pengujian tersebut pada tabel1. dibawah ini: 
Tabel 1. Hasil Pengujian Korelasi Rank Spearman Dengan Hipotesis

\begin{tabular}{|c|c|c|c|c|c|}
\hline No & Variabel & $\rho$ & Ket & Botudo & tō̄eñin-z \\
\hline 1 & Harga & $0.53 \%$ & Sedang & 4,408 & 1,677 \\
\hline 2 & Kualitas Produk & 0,604 & Kuat & 5,246 & 1,677 \\
\hline
\end{tabular}

Sumber: Data Diolah, 2018

Berdasarkan hasil penelitian dapat diketahui bahwa harga memiliki hubungan yang sedang dengan kepuasan pelanggan pada toko perlengkapan baju sekolah Elis Kota Bengkulu dengan nilai korelasi sebesar 0,537 berarti bahwa harga yang ditawarkan untuk para konsumen tidak terlalu mahal maupun tidak terlalu murah, karena produk yang mereka tawarkan adalah produksi sendiri hingga harga mereka

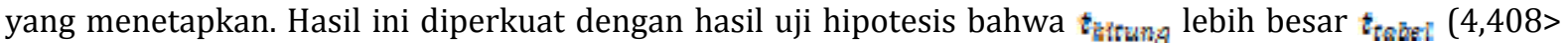
1,677). Dengan demikian hasil hipotesis adalah $H_{0 L}$ ditolak dan $R_{\Omega L}$ diterima. Artinya harga mempunyai hubungan yang signifikan dengan kepuasan pelanggan pada toko perlengkapan baju sekolah Elis Kota Bengkulu.

Hasil penelitian ini menggambarkan antara harga dengan kepuasan pelanggan memiliki hubungan positif. Namun bagi konsumen harga bukanlah prioritas utama karena konsumen lebih memilih bahan produk yang baik yang ditawarkan oleh toko perlengkapan baju sekolah Elis Kota Bengkulu. Hal ini sesuai dengan pendapat Irawan (2007:92) yaitu komponen harga ini relatif tidak penting bagi konsumen yang tidak sensitif terhadap harga.

Hasil penelitian korelasi rank spearman untuk hubungan kualitas produk terdapat hubungan yang kuat antara kualitas produk dengan kepuasan pelanggan pada toko perlengkapan baju sekolah Elis Kota Bengkulu dengan nilai korelasi sebesar 0,604. Hal ini diperkuat dengan hasil uji hipotesis bahwa tmrung lebih besar dari $t_{\text {tatel }}(5,246>1,677)$. dengan demikian hasil hipotesis adalah $H_{02}$ ditolak dan $\Pi_{\ltimes 2}$ diterima. Artinya kualitas produk mempunyai hubungan yang signifikan dengan kepuasan pelanggan pada toko perlengkapan baju sekolah Elis Kota Bengkulu.

Hasil penelitian ini sesuai dengan pendapat menurut Kotler dan Amstrong (2009:152) kualitas produk menggambarkan sejauh mana kemampuan produk tersebut dalam memenuhi kebutuhan konsumen.

\section{KESIMPULAN}

Berdasarkan hasil penelitian berkenaan dengan hubungan harga dan kualitas produk dengan kepuasan pelanggan pada toko perlengkapan baju sekolah Elis Kota Bengkulu dapat disimpulkan sebagai berikut:

a. Harga memiliki hubungan yang sedang dengan kepuasan pelanggan pada toko perlengkapan baju sekolah Elis Kota Bengkulu dengan nilai korelasi sebesar $n_{2}: 37$, berarti bahwa harga yang ditawarkan oleh pihak toko perlengkapan baju sekolah Elis Kota Bengkulu relatif sedang atau tidak terlalu mahal maupun tidak terlalu murah. Karena produk yang mereka tawarkan adalah produksi sendiri hingga

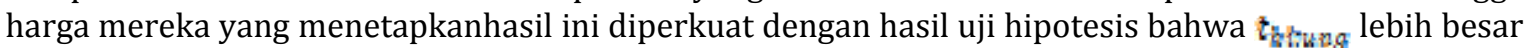
dari $t_{\text {tab̆ }}(4,408>1,677)$. Artinya harga mempunyai hubungan yang signifikan dengan kepuasan pelanggan pada toko perlengkapan baju sekolah Elis Kota Bengkulu.

b. Hubungan kualitas produk dengan kepuasan pelanggan pada toko perlengkapan baju sekolah Elis Kota Bengkulu memiliki korelasi yang kuat dengan nilai korelasi sebesar 0,504, berarti bahwa semakin baik kualitas yang di perjual belikan oleh toko perlengkapan baju sekolah Elis kota Bengkulu maka akan semakin tinggi juga tingkat kepuasan pelanggan pada perlengkapan baju sekolah pada toko Elis kota Bengkulu. Hal ini diperkuat dengan hasil uji hipotesis bahwa $t_{\text {hîtung }}$ lebih besar dari $t_{\text {tab̆ei }}$ $(5,246>1,677)$. Artinya kualitas produk mempunyai hubungan yang signifikan dengan kepuasan pelanggan pada toko perlengkapan baju sekolah Elis Kota Bengkulu.

\section{Saran}

Disarankan kepada toko perlengkapan baju sekolah Elis Kota Bengkulu untuk lebih memperbaiki harga agar konsumen merasa lebih dan nyaman dengan harga yang ditetapkan dan pertahankan kualitas produk yang telah membuat para konsumen atau pelanggan setia dengan produk yang diberikan.

\section{DAFTAR PUSTAKA}

Amir , M Taufik. 2008. Dinamika Pemasaran . jelajahi \& rasakan . Jakarta : PT. Raja Grafindo Persada. Daniel \& Gates . 2007. Riset Pemasaran Komtemporer. Salemba Empat Jakarta 
Heizer, jay dan Barry Render 2001. Operation Management. New Jersey: Prentce Hall

Giese, J. \& Cote J.A. 2000. Defining Consumer Satisfaction. Academy of Marketing Science Review .4. 1-24.

Kotler, dan Armstrong. 2008. Prinsip-prinsip Pemasaran I. Alih Bahasa Damos Sihombing, Edisi Keduabelas , Erlangga : Jakarta.

Kotler, Philip. 2007. Manajemen Pemasaran I : Edisi keduabelas Jakarta PT. Indeks. 2008. Manajemen Pemasaran .Edisi Millinium: PT. Prenhallindo, Jakarta 2009. Manajemen Pemasaran. Analisis Perencanaan. Implementasi dan kontrol. Edisikesembilan (edisi Indonesia). Alih bahasa Hendra Teguh dan Ronny A. Rusli. Prenhalindo: Jakarta

Kotler \& Keller. 2007. Manajemen Pemasaran , Jilid I, Edisi Kedua Belas, PT.Indeks: Jakarta

Mitior, M., \& Susena, K. C. Analisis Hubungan Pelayanan dengan Kepuasan Pelanggan pada Bengkel Candera Motor di Kaur Utara Kabupaten Kaur. Ekombis Review, 2(1).

Nopianto, 2015. Hubungan harga dan kualitas produk dengan kepuasan pelanggan Rumah Makan Padang Panjang Bintuhan. Skipsi Manajemen Fakultas Ekonomi Universitaa Dehasen Bengkulu

Putri, 2017 . Hubungan kualitas Produk , Harga dan Promosi dengan keputusan Pembelian Toyota Rush pada Agung Auto Mall. Skipsi Manajemen Fakultas Ekonomi Universitaa Dehasen Bengkulu

Oliver, Band 2007, Membangun Kepuasan Pelanggan, Gramedia Pustaka Utama : Jakarta.

Simamora, Bilson 2007. Panduan Riset dan Prilaku Konsumen. PT. Gramedia Pustaka Utama : Jakarta.

Stanton, William J . 2010. Prinsip Pemasaran. Cetakan ketujuh. Jakarta : Penerbit Erlangga

Sugiyono, 2013. Metode Penelitian Kuantitatif Kualiatif dan $R$ \& D. Cetakan ke -18 . Bandung: Alfabeta.

Suwarman, Ujang. 2011. Prilaku Konsumen teori dan Penerapannya Dalam Pemasaran. Penerbit: PT Ghalia Indonesia, Bogor.

Swastha, Basu, Sokotjo Ibnu. 2008. Pengantar Bisnis Modern. Cetakan ketiga Liberty Yogyakarta:

Tjiptono, Fandy, 2007. Manajemen Pemasaran Jasa. Edisi kedua Yogyakarta :Penerbit Andi. 